\title{
Abdominal compartment syndrome caused by gastric distension in bulimia nervosa and fatal injury following surgical decompression - A case report -
}

Received August 20, 2019

Revised November 15, 2019

Accepted November 19, 2019

\author{
Corresponding author \\ Helen Ki Shinn, M.D., Ph.D. \\ Department of Anesthesiology and \\ Pain Medicine, Inha University \\ Hospital, Inha University School of \\ Medicine, 27 Inhang-ro, Jung-gu, \\ Incheon 22332, Korea \\ Tel: 82-32-890-3968 \\ Fax: 82-32-881-2476 \\ E-mail: helenshinn@hanmail.net
}

\section{Byeong Hun Eom, Hyun Kyoung Lim, Nayoung Tae, and Helen Ki Shinn}

Department of Anesthesiology and Pain Medicine, Inha University Hospital, Inha University School of Medicine, Incheon, Korea

\begin{abstract}
Background: Abdominal compartment syndrome (ACS) occurs due to increased abdominal cavity pressure, causes multiple organ damage, and leads to fatal consequences. Increased intraperitoneal pressure due to different reasons generally does not result in serious damage, due to the compliance of the abdominal wall. However, when the pressure exceeds the limit, ACS develops, thereby causing fatal damage to the organs.

Case: A patient presented with rapid stomach swelling due to excessive food intake and was known to have bulimia nervosa, which had now resulted in ACS. Mental changes, abdominal distension, color change in the legs, acute kidney injury, and acidosis were seen. The patient expired due to ischemia-reperfusion injury and disseminated intravascular coagulation, which occurred after surgical decompression.
\end{abstract}

Conclusions: Under suspected ACS conditions, we should be aware of various symptoms that can occur. Early attempts for decompression are helpful, and it is important to be prepared for reperfusion injury prior to surgical decompression attempts.

Keywords: Bulimia; Intra-abdominal hypertension; Reperfusion injury; Shock, hemorrhagic.
Abdominal compartment syndrome (ACS) is a disease that causes multiple organ damage as a consequence of edema or increased pressure in the abdominal tissue, due to factors such as sepsis, abdominal trauma, excessive fluid supply, hematoma, abdominal tumor, or ascites. While ACS may occur due to various causes that increase the intra-abdominal pressure (IAP), an increase in IAP within a certain range does not cause organ damage due to abdominal wall compliance. Therefore, cases of ACS due to gastrointestinal distension caused by excessive food intake are not commonly reported.

Along with a literature review, the authors seek to report their experience with a bulimia nervosa patient, who had developed ACS due to excessive eating, and in whom ischemia-reperfusion injury, and disseminated intravascular coagulation (DIC) occurred after surgical decompression, leading to death.

\section{CASE REPORT}

The present case report was published with the prior consent of the patient's guardians.

A 23-year-old, $168 \mathrm{~cm}$ tall female patient, weighing $42 \mathrm{~kg}$, visited the emergency room with a chief complaint of abdominal pain. The abdominal pain, accompanied by nausea and vomiting, kept increasing gradually for eight hours.

This is an Open Access article distributed under the terms of the Creative Commons Attribution Non-Commercial License (http://creativecommons.org/licenses/by-nc/4.0) which permits unrestricted non-commercial use, distribution, and reproduction in any medium, provided the original work is properly cited.

Copyright (C) the Korean Society of Anesthesiologists, 2020 
The patient was diagnosed with major depression and bulimia nervosa nine years ago. The patient also had a history of frequent vomiting after episodes of binge eating, along with numerous suicide attempts. Ten hours before reporting to the hospital, the patient ate a very large quantity food, equivalent to approximately ten portions; however, the quantity of the vomit was much less, relative to the amount of food taken. The physical examination revealed abdominal pain and distension in the entire region, along with tenderness, but no rebound tenderness. Subsequent abdominal computed tomography (CT) revealed clear gastric distension. The results of various blood tests were normal. In the joint general surgery consultation that followed, it was decided that an immediate surgical treatment was not necessary; hence, the need for continuous observation of the condition was explained, and a gastroenterological or psychiatric hospitalization was advised, but both the patient and her guardians declined hospitalization. Afterward, they were warned of the possible complications, such as electrolyte imbalance, aspiration pneumonia, gastrointestinal perforation, ischemic changes, due to the pressure applied by gastrointestinal distension, and the possibility of death, in case the condition worsened. The self-discharge form was signed, and they returned home.

Seven hours after returning home, the patient re-visited the emergency room due to persistent abdominal pain, and mental confusion. At the time of the visit, the patient was unconscious. On physical examination, a more severe abdominal distension, and signs of abdominal rigidity were observed. Both legs of the patient had turned pale in color. No auscultation sounds were heard over the abdomen, and the dorsalis pedis pulse was not felt on either foot. Shock was suspected due to a $60 / 40 \mathrm{mmHg}$ blood pressure, 160 beats/min heart rate, 22 times/minute aspiration rate, and $36.4^{\circ} \mathrm{C}$ temperature. Other findings included $\mathrm{pH}$ 7.076, $\mathrm{PaCO}_{2} 22.3 \mathrm{mmHg}, \mathrm{PaO}_{2} 122 \mathrm{mmHg}, \mathrm{HCO}_{3}$ $6.3 \mathrm{mM} / \mathrm{L}$, base excess (BE) $23.7 \mathrm{mM} / \mathrm{L}$, and lactic acid 11.1 $\mathrm{mM} / \mathrm{L}$, which were measured in the arterial blood gas analysis and, thus, metabolic acidosis was confirmed. The electrolyte levels $\mathrm{Na}^{+} 157 \mathrm{mM} / \mathrm{L}, \mathrm{K}^{+} 6.2 \mathrm{mM} / \mathrm{L}$, and $\mathrm{Cl}^{-} 130 \mathrm{mM} / \mathrm{L}$, indicated that the electrolyte imbalance was severe (Table 1). In addition, the patient was in a severe hypoglycemic state with a blood sugar level of $15 \mathrm{mg} / \mathrm{dl}$; because of an elevated creatinine level of $2.84 \mathrm{mg} / \mathrm{dl}$, acute renal failure was suspected. First, to treat the metabolic acidosis, sodium bicarbonate was set at $80 \mathrm{mEq} / \mathrm{h}$. In the abdominal X-ray, the gastrointestinal tract (GIT) was seen to be filled with a large amount of food but without any bowel gas (Fig. 1). Abdominal CT re-

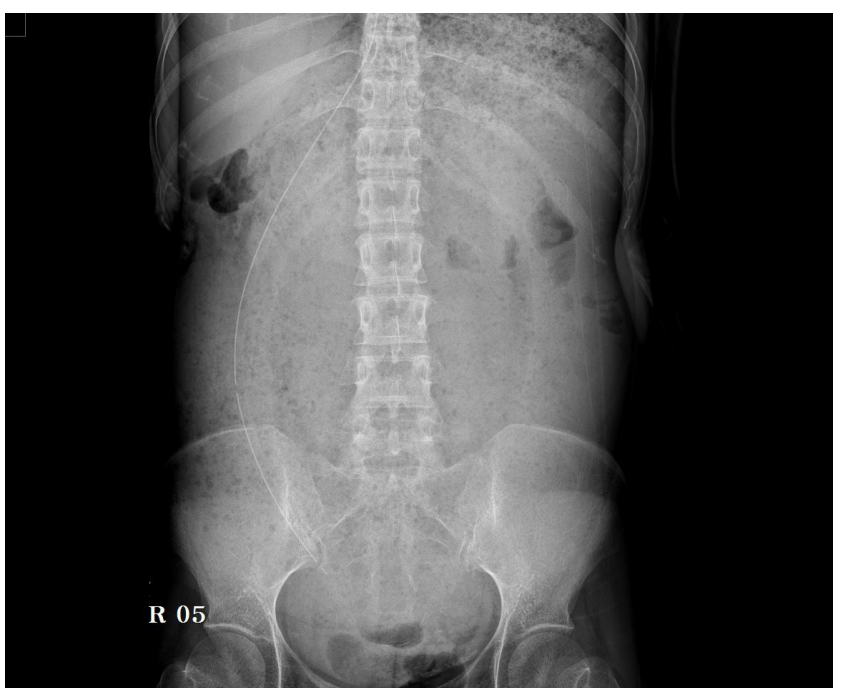

Fig. 1. The plain abdominal X-ray image shows markedly dilated state in stomach with abundant food materials.

Table 1. Changes in Arterial Blood Gas Analysis

\begin{tabular}{|c|c|c|c|c|c|c|c|}
\hline & Time & $\mathrm{pH}$ & $\mathrm{pCO}_{2}(\mathrm{mmHg})$ & $\mathrm{HCO}_{3}^{-}(\mathrm{mM} / \mathrm{L})$ & $\mathrm{Hb}(\mathrm{g} / \mathrm{dl})$ & $\mathrm{Na}^{+}(\mathrm{mM} / \mathrm{L})$ & $\mathrm{K}^{+}(\mathrm{mM} / \mathrm{L})$ \\
\hline Re-visit ER & $21: 23$ & 7.07 & 22.3 & 6.3 & 14.9 & 157 & 6.2 \\
\hline Prior to OP & 01:03 & 7.43 & 21.5 & 14.1 & & 164 & 4 \\
\hline OP starts & 03:20 & & & & & & \\
\hline 1st & 03:25 & 7.45 & 20.8 & 14.4 & 6.8 & 161 & 3.8 \\
\hline 2nd & 03:57 & 6.75 & 46 & & 6.5 & 146 & 7.5 \\
\hline 3rd & 04:09 & 7.01 & 33.9 & 8.4 & 4.3 & 157 & 6.7 \\
\hline 4th & $04: 28$ & 6.98 & 22.1 & 5.2 & 5.9 & 154 & 6.7 \\
\hline 5th & $04: 42$ & 6.94 & 18.1 & 3.8 & 6.7 & 138 & 6 \\
\hline OP ends & 05:05 & & & & & & \\
\hline ICU arrival & 05:20 & 7.29 & 48.8 & 23.3 & 3.5 & 148 & 6.7 \\
\hline Expired* & 08:10 & 6.91 & 34.4 & 7 & 1.8 & & \\
\hline
\end{tabular}

$\mathrm{Hb}$ : hemoglobin, ER: emergency room, OP: operation, ICU: intensive care unit. * 5 min before the patient expired. 
vealed a very large dilation of the stomach, esophagus, and the second part of the duodenum; it was suspected that the distended organs were pressing against the descending aorta, and the right kidney was pressed upwards (Fig. 2). One hour after the emergency room re-visit, the patient's mental state became lethargic-communication became impossible and spontaneous respiration decreased; as $\mathrm{SpO}_{2}$ was measured to be $88 \%$, endotracheal intubation was performed. A Foley catheter was then inserted, but no urine was drained; an emergency hemodialysis was prepared, and for enough fluid supply, a central venous catheter was inserted into the right jugular vein. For continuous monitoring of changes in the vital signs, a conduit was placed in the right radial artery. An attempt was made to insert a nasogastric tube to relieve gastrointestinal pressure, but the food was not drained due to a blockage near
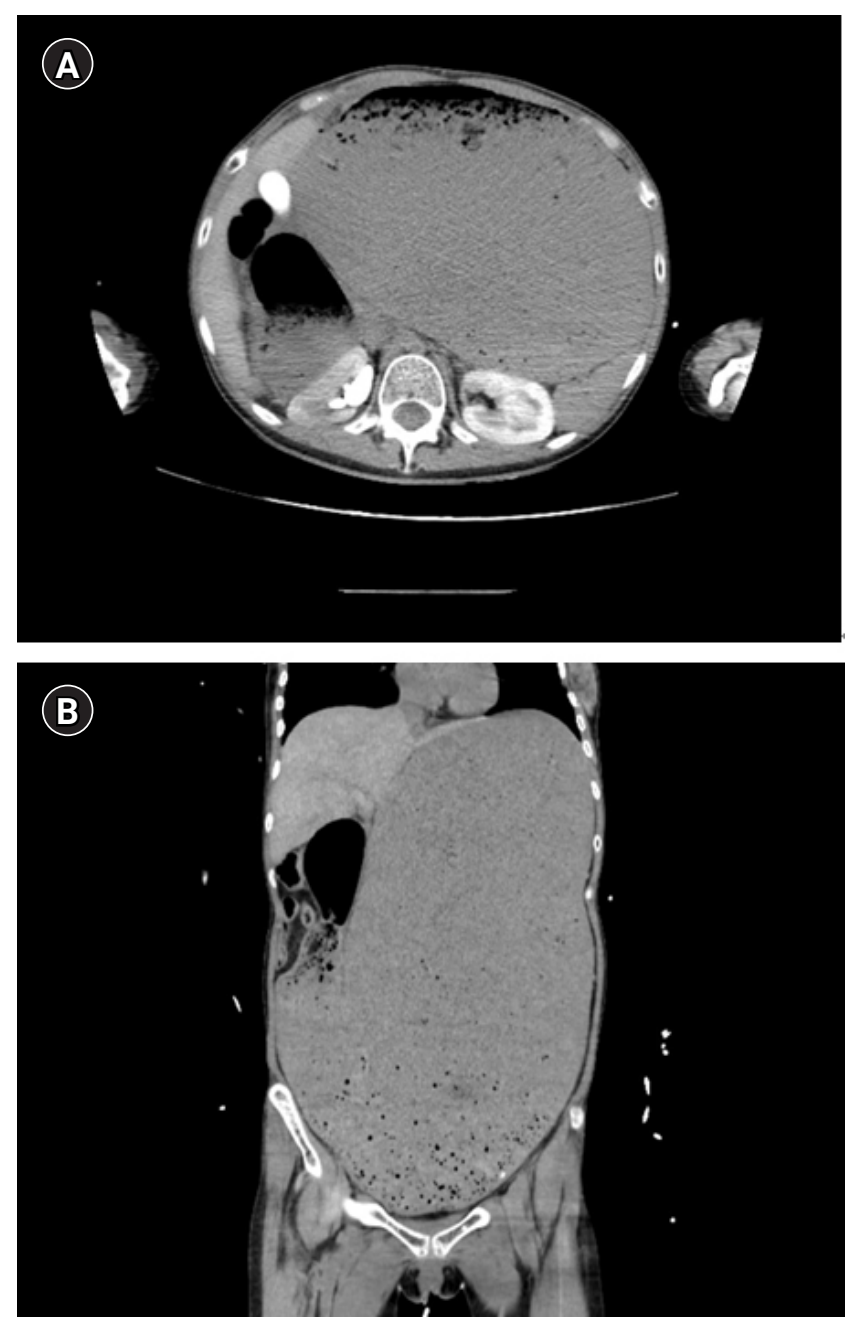

Fig. 2. The abdomen-pelvis computed tomography axial (A) and coronal (B) images revealing markedly distended stomach, dilated distal esophagus and proximal duodenum. the esophagus, which made further insertion impossible. An abdominal CT performed for follow-up observation revealed that the abdomen was still filled with food, and the nasogastric tube was twisted at the end of the esophagus (Fig. 3). It was also suspected that insertion was not possible due to gastroesophageal junction deviation or esophageal stenosis; however, no such sign was seen.

There was no decompression through the nasogastric tube, and as time passed, the mental state of the patient changed into a state of confusion. The patient's vital signs became increasingly unstable. Since the symptoms and follow-up blood test results exacerbated, instead of performing a percutaneous drainage, it was decided to attempt a surgical decompression; subsequently, the patient was transferred to the operation room six hours after the re-visit. In the emergency room, a total of 3,170 $\mathrm{ml}$ of crystalloid fluid, in which a $5 \%$ glucose solution was included, was administered. Urine volume was not measured.

After reaching the operation room, the patient's blood pressure was $70 / 46 \mathrm{mmHg}$ and the heart rate was 128 beats/min. First, in order to improve the vital signs, crystalloid fluid was administered at the highest speed via the right arm's peripheral venous catheter and via the central venous catheter of the right internal jugular vein. The in-
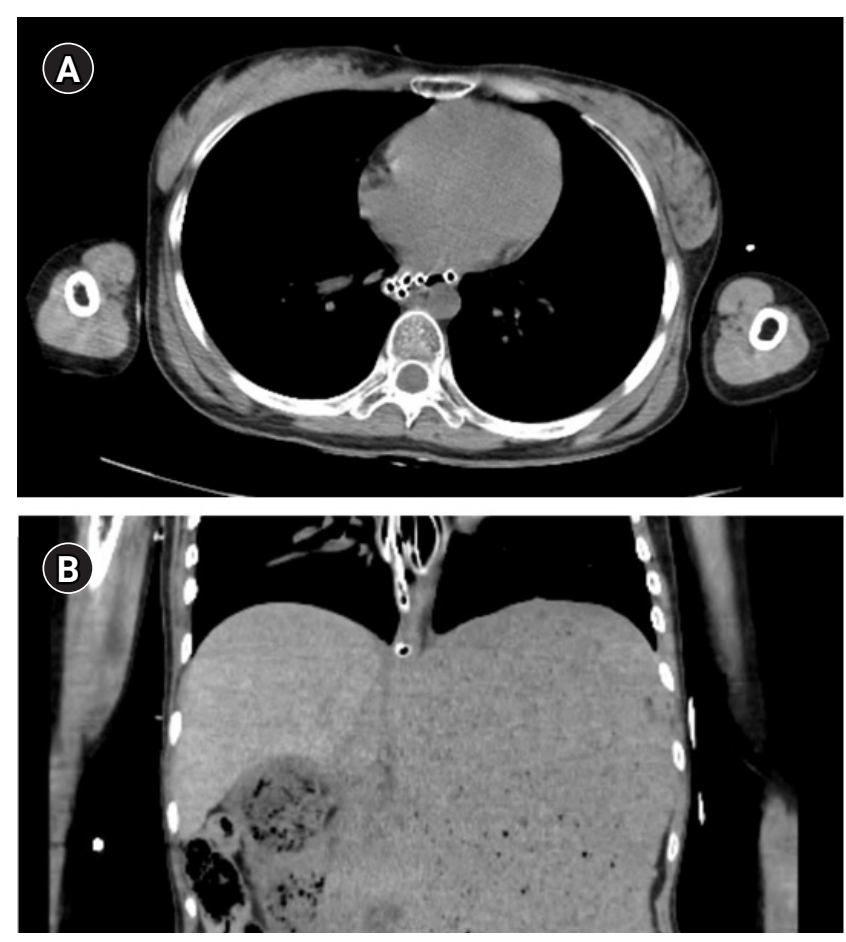

Fig. 3. Axial (A) and coronal (B) images of the abdomen-pelvis computed tomography (CT). CT shows coiling of L-tube tip in distal esophagus. 
stillation of norepinephrine was initiated with sustained dosing at an additional rate of $0.2 \mu \mathrm{g} / \mathrm{kg} / \mathrm{min}$, and continuous infusion of vasopressin at $4-8 \mathrm{unit} / \mathrm{h}$ was also initiated. Subsequently, general anesthesia was induced using sevoflurane 1-2 vol\% and rocuronium $50 \mathrm{mg}$. In the arterial blood gas analysis conducted after entering the operating room, pH 7.45, $\mathrm{PaCO}_{2} 20.8 \mathrm{mmHg}, \mathrm{PaO}_{2} 335 \mathrm{mmHg}, \mathrm{Na}^{+}$ $161 \mathrm{mM} / \mathrm{L}, \mathrm{K}^{+} 3.8 \mathrm{mM} / \mathrm{L}$, glucose $205 \mathrm{mg} / \mathrm{dl}$, lactate 13 $\mathrm{mM} / \mathrm{L}$, hemoglobin $6.8 \mathrm{~g} / \mathrm{dl}$, and $\mathrm{HCO}_{3}{ }^{-} 14.4 \mathrm{mM} / \mathrm{L}$ were measured (Table 1). Four units of erythrocytes were prescribed to correct the reduced hemoglobin, and $20 \mathrm{mg}$ of furosemide was injected due to a continuous lack of urination. Furthermore, for rapid transfusion, the rapid infusion system (RIS) was connected to the central venous catheter of the right internal jugular vein, and the transfusion of four erythrocyte units was initiated.

The operating surgeon planned and performed a gastrotomy, after making a skin incision of approximately $10 \mathrm{~cm}$ and within 20 min of beginning the surgery. The food and $5,000 \mathrm{ml}$ of body fluid present in the stomach were drained via suction. Thirty minutes after the operation, blood pressure was maintained low at $60 / 40 \mathrm{mmHg}$ and almost all food was drained; as a large amount of continuous gastric bleeding occurred after decompression, a total of 6,000 ml was drained into the suction bottle. In the follow-up arterial blood gas analysis, results showed: $\mathrm{pH} 6.75, \mathrm{PaCO}_{2} 46$ $\mathrm{mmHg}$, and lactate $20 \mathrm{mM} / \mathrm{L}$. Acidosis had worsened, the blood sugar level had significantly increased to $469 \mathrm{mg} / \mathrm{dl}$, electrolyte imbalance had exacerbated with $\mathrm{K}^{+} 7.5 \mathrm{mM} / \mathrm{L}$, and hemoglobin had fallen to $4.3 \mathrm{~g} / \mathrm{dl}$, suggesting a large amount of bleeding. To correct this, $60 \mathrm{mEq}$ of sodium bicarbonate, and two units of insulin were administered. Further, $1.2 \mathrm{~g}$ of calcium chloride was administered to treat hyperkalemia. Moreover, additional $20 \mu \mathrm{g}$ of epinephrine was injected to correct persistent hypotension.

Bleeding in the stomach continued, and despite initiating erythrocyte transfusion via RIS, hemoglobin level decreased. As a result, a large amount of internal bleeding was suspected, and additional eight units of erythrocytes, and eight units of fresh frozen plasma were prescribed. The operating surgeon tried to determine the cause and area of bleeding, but as the surgical incision was only $10 \mathrm{~cm}$, abdominal organs other than the stomach could not be identified with the naked eye. To reduce bleeding, the operating surgeon considered performing a total gastrectomy or extending the abdominal incision to confirm the bleeding areas from, other organs but concluded that the bleeding was due to ischemia-reperfusion injury after surgical decompression, and DIC. Since the patient's vital signs steadily worsened, it was decided that the abdomen be closed urgently, and the patient moved to the intensive care unit (ICU).

One hour after the start of the operation, suturing after gastrectomy was completed. When the closing of the abdomen started, non-invasive blood pressure was not measured, and flat waveforms were observed in the catheter of the right radial artery. There was no pulse detected via palpation, and after confirming pulseless electrical activity through the observation of electrocardiogram, an additional $1 \mathrm{mg}$ of epinephrine was injected, and cardiopulmonary resuscitation (CPR) was initiated.

A total of $3 \mathrm{mg}$ of epinephrine was injected, with cardiac rhythm monitoring at 2 min intervals; afterward, 2 units of vasopressin were injected at 2 min intervals, totaling an injection of 4 units of vasopressin. After completing the abdominal closure while performing CPR, the patient was transferred to the intensive care unit, and no urine output was seen until the patient left the operation room.

The operation was conducted for $1 \mathrm{~h} 20 \mathrm{~min}$, and the anesthesia time was $1 \mathrm{~h} 50 \mathrm{~min}$. During the operation, a total of $800 \mathrm{ml}$, four erythrocyte units, were transfused, and $6,200 \mathrm{ml}$ of crystalloid fluid were administered. A total of $6,000 \mathrm{ml}$ was drained into the suction bottle- $-5,000 \mathrm{ml}$ of food and body fluid through the suction unit via gastrectomy, and $1000 \mathrm{ml}$ due to bleeding that had occurred after decompression from the start of the operation until finish; however, as mentioned earlier, the incision area was small, and bleeding occurring from other abdominal organs could not be confirmed, making it difficult to estimate the exact estimated blood loss. Additionally, prescribed erythrocytes and fresh frozen plasma were transfused through the RIS as the patient left the operation room.

After entering the ICU, CPR was stopped due to a return of spontaneous circulation, but the existing usage of epinephrine, norepinephrine, and vasopressin was preserved, and transfusion continued. However, blood pressure was still not measured, an additional 1,000 $\mathrm{ml}$ of bleeding was confirmed through the nasogastric tube, and bleeding from the closed abdominal area continued. Subsequently, as 3.5 $\mathrm{g} / \mathrm{dl}$ hemoglobin was measured in the follow-up test, transfusion continued, and a 113.1-second prothrombin time, 180-s activated partial thromboplastin time, and platelet count of $22,000 / \mu \mathrm{l}$ were found, confirming that the patient was in a state of DIC. Despite continuous drug administra- 
tion and transfusion, the hemoglobin level decreased to 1.8 $\mathrm{g} / \mathrm{dl}$, and after three hours in the ICU, the heartbeat disappeared, and the patient was declared dead.

\section{DISCUSSION}

Dozens of cases have been reported that required surgical treatment due to bulimia nervosa, mentioned the problems caused by gastrointestinal necrosis or perforation, or addressed the problems associated with the occurrence of ACS. However, such a case is not commonly reported, in which ACS occurred due to rapid abdominal distension without perforation or necrosis, due to binge eating, and surgical decompression was performed without effective prior decompression, causing hypovolemic shock due to massive hemorrhage caused by ischemia-reperfusion injury and DIC, ultimately leading to death.

Kim et al. [1] and Youm et al. [2] reported similar cases. In the case report by Kim et al. [1], while gastrointestinal distension, abdominal pain, and leg color changes due to overeating were shown before surgical decompression, vital signs and blood test results were close to normal, and no signs of other organ failures were seen, thus showing no clear symptoms of ACS. In the case report by Youm et al. [2], changes in the vital signs and mental state also occurred two hours after admission. However, in this case, acute renal failure and acidosis were present since the hospital visit, and severe ACS symptoms were seen even before decompression, including mental state changes and respiratory failure.

To understand ACS, it is important to first differentiate between ACS and intra-abdominal hypertension (IAH). The common feature of the two is that IAP increases above the normal level. IAP is defined as the pressure in the abdomen, and $5-7 \mathrm{mmHg}$ is considered normal. While IAH is defined as a state in which IAP is above $12 \mathrm{mmHg}$, ACS not only means a state of increased IAP but also a state in which IAP is above $20 \mathrm{mmHg}$, accompanied by a new or ongoing organ dysfunction. When the increase in abdominal pressure (AP) exceeds the abdominal wall compliance, the supply of blood and oxygen to the organs becomes restricted, and the increased pressure causes fluids to penetrate into the various organs of the abdomen, further increasing the pressure, thereby causing organ failure [3].

IAH, which can be considered as the stage before ACS, can also cause various severe complications. The World Society of the Abdominal Compartment Syndrome (WSACS) recommends measuring IAP in patients who possess risk factors for IAH or ACS, since IAH is correlated with patients' morbidity and mortality and, therefore, treating and preventing it are important [3]. The reported risk factors include abdominal surgery, major trauma, prone position, and intra-abdominal infection. Among these circumstances which were included as risk factors, gastrointestinal swelling, acidosis, and sepsis, were present in our case, suggesting a high possibility of ACS [3].

As mentioned above, IAP is important because through it, the patient's present state and prognosis can be predicted, and it is correlated with mortality. According to Kirkpatrick et al. [3], IAP grades can be divided into Grade I = IAP 12 to $15 \mathrm{mmHg}$, Grade II = IAP 16 to $20 \mathrm{mmHg}$, Grade $\mathrm{III}=\mathrm{IAP} 21$ to $25 \mathrm{mmHg}$, and Grade IV = IAP > $25 \mathrm{mmHg}$. According to the study performed by Prasad et al. [4], a higher IAP grade significantly correlated with a higher mortality. In a Grade IV case, 71-85\% mortality has been reported [5].

In the IAP measuring method recommended by WSACS, saline solution is injected into the empty bladder and connects the inserted Foley catheter to the pressure transducer and monitor [3]. In their study, Flores-Alvarez et al. [6] also indirectly measured IAP to indirectly obtain an early ACS diagnosis and noted that anuria and grade III-IV IAH were the most important factors impacting mortality. In the present case, however, the IAP could not be measured due to a lack of time for IAP measurement and a lack of adequate equipment. According to Torquato et al. [7], increased IAP increases the airway pressure. With reference to this finding regarding the correlation between positive end expiratory pressure (PEEP) and IAP, given that the airway pressure increased to $28 \mathrm{cmH}_{2} \mathrm{O}$ immediately after anesthesia and dropped to $10 \mathrm{cmH}_{2} \mathrm{O}$ after surgical decompression under the same ventilator setting (volume control ventilation mode, $400 \mathrm{ml}$ tidal volume, 12 times/min respiration rate, $6 \mathrm{cmH}_{2} \mathrm{O}$ PEEP), we conjectured that the IAP in this case was in a significantly elevated state. Furthermore, Bailey and Shapiro [8] reported that from an IAP of 15-20 $\mathrm{mmHg}$, urine volume starts to decrease, and above 30 mmHg IAP, anuria occurs; taking into consideration that the patient in the present case was in a state of anuria, a high possibility of the patient having been in a grade IV state with an IAP above $30 \mathrm{mmHg}$ can be inferred. The aspect that could be considered responsible for causing such a decrease in kidney function is that in an increased IAP state, the inferior vena cava and portal vein are compressed 
due to pressure; venous return decreases and the intra-thoracic pressure increases, thereby reducing the flow of the superior and inferior vena cava and, thus, reducing the cardiac output. According to the report by Bailey and Shapiro [8], even after the restoration of cardiac output in a state of renal failure due to ACS, the impairment of kidney function did not recover. Through this observation, they reported that rather than the cause of renal failure being influenced by decreased cardiac output, if the parenchyma of the kidney was compressed, renal vascular resistance could increase from $500 \%$ to $1,500 \%$, and this phenomenon could increase the secretion of renin, antidiuretic hormones, and aldosterone, further increasing the renal vascular resistance and exacerbating renal dysfunction [8]. Therefore, it is necessary to anticipate that high grade IAH and high mortality rates may be present in cases of exacerbation and to prepare for active treatment.

Saggi et al. [9] reported that intestinal perfusion damage occurs at mucosal and submucosal levels in IAPs above 20 $\mathrm{mmHg}$, which reduces tissue oxygen tension and increases acidosis and free radical production. This ischemic damage, increased free radicals, and endotoxins lead to multiple organ failure [10]. Recent studies have revealed a correlation between increased IAPs above $10 \mathrm{mmHg}$ with sepsis, mortality, and multiple organ failure [9].

An important factor contributing to the death of patients with long-term failure due to ACS is ischemia-reperfusion injury. This means that the tissue damage occurs when tissues are reperfused after a period of ischemia, during which blood is not supplied or oxygenated for any reason. During the ischemic period, many changes occur in the cells; if ischemia persists, the cells die, or if reperfusion occurs in already changed cells, the cells generate free radicals. The resulting oxidative stress causes inflammatory and oxidative reactions that damage tissues. When this damage occurs in microvessels, the permeability of the cells increases, and fluids, including blood, easily escape the tissues $[11,12]$. Such tissue damage is likely to worsen organ failure and simultaneously cause massive hemorrhage and induce DIC.

Reperfusion syndrome can frequently occur during decompression surgery and be a cause of death. Rapid dilation of the abdominal and pelvic vein after decompression, and tissue damage and increased blood vessel permeability due to ischemia-reperfusion injury cause massive hemorrhage, leading to a state of low blood pressure, cardiac atrophy and ventricular arrhythmias, and resulting in high mortality [5]. Therefore, in order to prepare for the phenomenon of ischemia- reperfusion, systemic vascular resistance, and a rapid decrease of IAP after decompression, the administration of sufficient fluid is needed before decompression [9].

Since the problems caused by increased IAP are important, the treatment and prevention of IAH and ischemia-perfusion injury are also important. According to the ACS guideline published by the WSACS in 2013, it was recommended that anxiety and pain be reduced in patients through sedation and anesthesia to prevent and treat IAH; it also reported that temporary use of neuromuscular blockers can reduce IAP by reducing the abdominal muscle tension, and increasing abdominal compliance [3]. Macalino et al. [13] reported that neuromuscular blockers improved IAP, blood pressure, airway pressure, and urine output volume before surgery. Moreover, in case intraperitoneal fluid is clearly present in the abdominal cavity, percutaneous drainage was deemed to be helpful, and it was recommended to attempt a decompression via a nasogastric or rectal catheter if the GIT was enlarged. Diuretics, albumin, and dialysis, on the other hand, were not helpful and therefore, not recommended. While the aforementioned methods can improve the patients' state, ultimately a surgical method should be employed, and decompression laparotomy should be performed in order to reduce IAP and improve the organ function. Muresan et al. [14] investigated how decompression laparotomy could reduce mortality in patients with ACS. Treatment in this study used a four-step therapy protocol. The first step was to insert a nasogastric catheter into the patient, give an adequate sedation effect, and not to supply excessive fluids. Step two was to manage the edema of the tissue using diuretics and hypertonic or colloid solutions in a Trelendenburg position. Step three was to stop nutrition and insert a rectosigmoid aspiration catheter or puncture for discharge using ultrasound or CT to decompress the colon before mechanical ventilation after endotracheal intubation. In step four, despite the medical treatment, surgical decompression was attempted if the IAP remained above 20 mmHg after $24 \mathrm{~h}$ after IAP elevation. After decompression, the Vivano ${ }^{\circledR}$ Med Abdominal Kit (Paul Hartmann AG, Germany) was used to continuously lower IAP and reduce the tissue edema. The Vivano ${ }^{\circledR}$ Med Abdominal Kit used foams and layers to keep the abdominal wound open without suturing and to control the intraperitoneal pressure using a suction catheter connected to the foam. Several days later, 
suturing was performed after the IAP, and the wound was stabilized. The result of the study showed that surgical decompression reduced the mortality rate by $8.7 \%$. It was reported that the shorter time between the onset of ACS and decompression laparotomy, the better the prognosis; prognosis was poor in case the time exceeded $24 \mathrm{~h}$.

As previously mentioned, ischemia-reperfusion injury and shock due to DIC are more likely to occur after decompression laparotomy. In the report by Morris et al. [15], $1 \mathrm{~g}$ of $0.45 \%$ normal saline was mixed with $50 \mathrm{~g}$ mannitol and $50 \mathrm{mEq}$ sodium bicarbonate to minimize damage due to the reperfusion washout effect of the anaerobic byproducts, and providing sufficient volume prior to surgery, which helped in the reduction of ischemic reperfusion injury.

The unfortunate aspect in this case was that the wound was closed immediately after decompression laparotomy, and IAP was not controlled. Muresan et al. [14] reported that it is important to keep in mind that suturing the IAP with open wounds can improve patient condition and improve the survival rate.

In conclusion, we report a case in which bulimia nervosa increased IAP and progressed to ACS; after surgical decompression, a massive hemorrhage occurred due to ischemia-reperfusion injury and DIC, leading to a state of hypovolemic shock and ultimately death. If it is possible to measure IAP, the patient's state and prognosis can be predicted, but in emergency rooms, measuring IAP is realistically difficult; thus, evaluating the clinical symptoms that may occur in the patient, depending on the increase of IAP and progression of ACS, may be useful for the early detection and prediction of IAP and, thus, the occurrence of ACS. If the patient's condition is critical, AP should be relieved via surgical decompression as soon as possible, and nasogastric tube insertion and the use of neuromuscular blockers prior to surgery may be helpful in alleviating the patient's state. Prophylactic treatment with mannitol and sodium bicarbonate prior to decompression to minimize ischemia-reperfusion injury and suturing after adjusting IAP with open wound are expected to reduce mortality.

\section{SUPPLEMENTARY MATERIALS}

Supplementary data containing Korean version of this article is available at https://doi.org/10.17085/apm.2020. 15.2.251.

\section{CONFLICTS OF INTEREST}

No potential conflict of interest relevant to this article was reported.

\section{AUTHOR CONTRIBUTIONS}

Conceptualization: Hyun Kyoung Lim. Data acquisition: Nayoung Tae. Supervision: Helen Ki Shinn. Writing_original draft: Byeong Hun Eom.

\section{ORCID}

Byeong Hun Eom, https://orcid.org/0000-0001-8776-5855

Hyun Kyoung Lim, https://orcid.org/0000-0003-2694-1258

Nayoung Tae, https://orcid.org/0000-0001-7211-9527

Helen Ki Shinn, https://orcid.org/0000-0003-1703-5501

\section{REFERENCES}

1. Kim BS, Kwon JW, Kim MJ, Ahn SE, Park HC, Lee BH. Abdominal compartment syndrome caused by a bulimic attack in a bulimia nervosa patient. J Korean Surg Soc 2011; 81 Suppl 1: S1-5.

2. Youm SM, Kim JY, Lee JR. Acute gastric dilatation causing fatal outcome in a young female with eating disorder: a case report. Korean J Anesthesiol 2015; 68: 188-92.

3. Kirkpatrick AW, Roberts DJ, De Waele J, Jaeschke R, Malbrain ML, De Keulenaer B, et al. Intra-abdominal hypertension and the abdominal compartment syndrome: updated consensus definitions and clinical practice guidelines from the World Society of the Abdominal Compartment Syndrome. Intensive Care Med 2013; 39: 1190-206.

4. Prasad GR, Subba Rao JV, Aziz A, Rashmi TM. The role of routine measurement of intra-abdominal pressure in preventing abdominal compartment syndrome. J Indian Assoc Pediatr Surg 2017; 22: 134-8.

5. Parsak CK, Sakman G. Acute gastric dilatation and abdominal compartment syndrome as complication of pyloric stenosis. Internet J Gastroenterol [serial on the Internet]. 2007; 5 [cited 2019 Jul 13]. Available from http://ispub.com/IJGE/5/2/6299/.

6. Flores-Alvarez E, Avila-Cuevas GE, de la Torre-González JC, Rivera-Barragán V, López-Rodríguez JL, Reynoso-Talamantes D. [Early diagnosis and risk factors associated with abdominal compartment syndrome]. Cir Cir 2005 73: 179-83. Spanish.

7. Torquato JA, Lucato JJ, Antunes T, Barbas CV. Interaction between intra-abdominal pressure and positive-end expiratory pressure. Clinics (Sao Paulo) 2009; 64: 105-12.

8. Bailey J, Shapiro MJ. Abdominal compartment syndrome. Crit 
Care 2000; 4: 23-9.

9. Saggi BH, Ivatury R, Sugerman HJ. Part XVI. Surgical critical care issues. In: Surgical treatment: evidence-based and problem-oriented. Edited by Holzheimer RG, Mannick JA: Munich, Zuckschwerdt. 2001. Available from https://www.ncbi.nlm. nih.gov/books/NBK6908/.

10. Yoshikawa T, Kondo M. Free radicals in multiple organ failure. Jpn J Med 1990; 29: 683-5.

11. Carden DL, Granger DN. Pathophysiology of ischaemia-reperfusion injury. J Pathol 2000; 190: 255-66.

12. Sun MS, Jin H, Sun X, Huang S, Zhang FL, Guo ZN, et al. Free radical damage in ischemia-reperfusion injury: an obstacle in acute ischemic stroke after revascularization therapy. Oxid
Med Cell Longev 2018; 2018: 3804979.

13. Macalino JU, Goldman RK, Mayberry JC. Medical management of abdominal compartment syndrome: case report and a caution. Asian J Surg 2002; 25: 244-6.

14. Muresan M, Muresan S, Brinzaniuc K, Voidazan S, Sala D, Jimborean $\mathrm{O}$, et al. How much does decompressive laparotomy reduce the mortality rate in primary abdominal compartment syndrome?: a single-center prospective study on 66 patients. Medicine (Baltimore) 2017; 96: e6006.

15. Morris JA Jr, Eddy VA, Blinman TA, Rutherford EJ, Sharp KW. The staged celiotomy for trauma. Issues in unpacking and reconstruction. Ann Surg 1993; 217: 576-84. 